\title{
RB608, RB609, RB610, RB611 and $R B 612$ antibodies recognize murine pancreatic polypeptide by ELISA
}

Marta Perez Frances, Fabrizio Thorel, Pedro L. Herrera

Department of Genetic Medicine and Development, Faculty of Medicine, University of Geneva, Geneva, Switzerland

\section{Abstract}

Newly generated recombinant antibodies RB608, RB609, RB610, RB611 and RB612 detect by ELISA the peptidic hormone termed pancreatic polypeptide (PPY).

\section{Introduction}

Pancreatic polypeptide (PPY, UniProt P10601) is a hormone secreted by pancreatic gamma cells (also known as PP cells) of the endocrine pancreas. It regulates pancreatic and gastrointestinal functions (Yonekura et al., 1988). Until the recent development of an efficient mouse monoclonal antibody, no reliable anti-PPY antibodies were commercially available (Hara et al., 2019). Here, we describe the ability of five recombinant antibodies (RB608, RB609, RB610, RB611 and RB612) to recognize mouse pancreatic polypeptide by ELISA.

\section{Materials \& Methods}

Antibodies: ABCD_RB608, ABCD_RB609, ABCD_RB610, ABCD_RB611 and ABCD_RB612 antibodies (ABCD nomenclature, https://web.expasy.org/ abcd/) were produced by the Geneva Antibody Facility (https:/www.unige.ch/medecine/antibodies/) as miniantibodies with the antigen-binding $\mathrm{VHH}$ portion fused to a mouse IgG2A Fc. HEK293 suspension cells (growing in FreeStyle $^{\text {TM }} 293$ Expression Medium, Gibco 12338) were transiently transfected with the vector coding for the VHH-Fc of each antibody. Supernatants ( $\sim 50-100 \mathrm{mg} / \mathrm{L})$ were collected after 4 days.

Antigen: The antibodies were raised against a Nbiotinylated synthetic peptide corresponding to the processed, mature form (residues 30-65) of the murine pancreatic polypeptide (APLEPMYPGDYATPEQMAQYETQL RRYINTLTRPRY). As control, an irrelevant peptide (HFERPRGPRLGYSIPSRSGASGLDKRDYV, from human CLDN9, UniProt O95484) was used.

Protocol: The whole procedure was carried out at room temperature. Biotinylated peptides at saturating concentration (10 pmol/well) were immobilized on streptavidin-coated ELISA plates (Pierce 15124) for 30 min. Each well was rinsed three times with $100 \mu \mathrm{l}$ of washing buffer (PBS $+0.5 \%(\mathrm{w} / \mathrm{v}) \mathrm{BSA}+0.05 \%(\mathrm{w} / \mathrm{v})$ Tween20), then incubated for 1 hour with $50 \mu 1$ of RB antibody-containing supernatant diluted in washing buffer. After rinsing 3 times (100 $\mu 1$ washing buffer), wells were incubated with horseradish peroxidase-coupled goat anti-mouse IgG (BioRad 170-6516, dilution 1:1000, $50 \mu \mathrm{l}$ per well) for $30 \mathrm{~min}$. After 5 rinses, Tetramethylbenzidine (TMB) substrate (Sigma T5569) was added (50 $\mu$ l per well). The reaction was stopped by the addition of $25 \mu 1$ of $2 \mathrm{M} \mathrm{H}_{2} \mathrm{SO}_{4}$. The absorbance (OD) was measured at 450 nm.

\section{Results}

Antibodies RB608, RB609, RB610, RB611 and RB612 bound in a concentration-dependent manner to a peptide comprising residues 30-65 of murine PPY, but not to an irrelevant control peptide (Fig. 1).

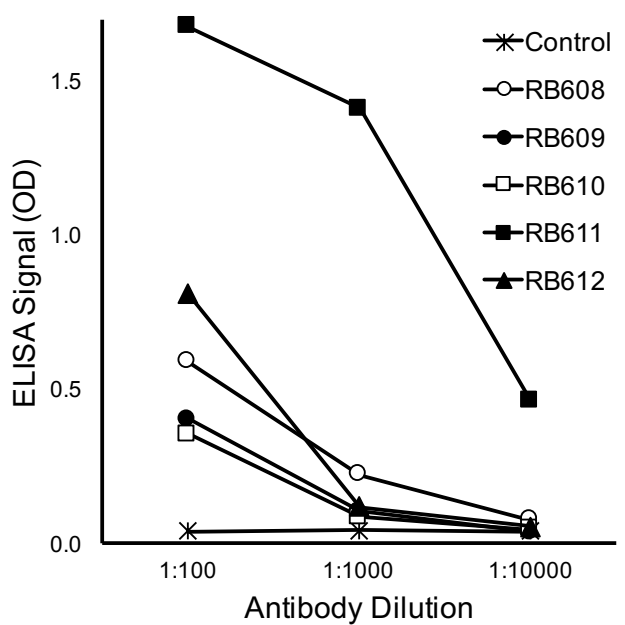

Fig. 1. RB608, RB609, RB610, RB611 and RB612 antibodies bind specifically to murine pancreatic polypeptide, but not to an irrelevant control peptide, as detected by ELISA. Control is shown only for RB608; all other background curves are superimposed.

\section{References}

Hara A, Nakagawa Y, Nakao K, et al. Development of monoclonal mouse antibodies that specifically recognize pancreatic polypeptide. Endocr J. 2019; 66(5):459-468. PMID: 30842364.

Yonekura H, Nata K, Watanabe T, Kurashina Y, Yamamoto H, Okamoto H. Mosaic evolution of prepropancreatic polypeptide. II. Structural conservation and divergence in pancreatic polypeptide gene. J Biol Chem. 1988; 263(6):2990-7. PMID: 3343236.

\section{Conflict of interest}

The authors declare no conflict of interest. 